\title{
FAMÍLIA NO PROCESSO DE ALFABETIZAÇÃO
}

\author{
Elisa Maria Pitombo ${ }^{1}$ \\ Sedes Sapientiae - SP
}

Sonia Madi

Cenpec-SP

\section{RESUMO}

O presente trabalho fornece um relato da experiência do Letra Móvel $^{1}$ durante os anos de 2020 e 2021. Crianças do primeiro ano do Ensino Fundamental de uma escola pública da zona leste de São Paulo foram atendidas por vídeo chamadas por alfabetizadoras com a colaboração das famílias, eixo fundamental do processo de ensino aprendizagem. Nesse trabalho refletimos sobre os deslocamentos necessários para que a casa e as relações familiares abrissem espaço, dedicassem tempo e se reorganizassem para possibilitar a continuidade da aprendizagem de seus filhos. Desenvolvemos interações, estratégias e didáticas que garantissem a presença da escrita com função social com sentido para as crianças e famílias. A sintonia com as necessidades e interesses das crianças, a escuta e os diálogos com as famílias, a reflexão contínua entre as alfabetizadoras foram essenciais para o desenvolvimento do trabalho.

Palavras- chave: família; alfabetização; letramento; ensino remoto.

\footnotetext{
${ }^{1}$ Elisa Maria Pitombo: Mestre em Psicologia USM, S P - elisamariapitombo@gmail.com

2 Sonia Madi: Mestre em Didática FEUSP - soniammadi@gmail.com
} 


\section{FAMILY IN THE LITERACY PROCESS}

\section{ABSTRACT}

The present work provides an account of the experience of Letra Móvel, during the Years 2020 and 2021. Children in the first year of Elementary School in a public school in the east side of São Paulo were assisted by video calls by literacy teachers with the collaboration of their families, fundamental axis of the teaching-learning process. In this work, we reflected on the displacements necessary for the home and Family relationships to open up space, dedicate time and reorganize themselves to enable the continuity of their children learning. We developed interactions, strategies and didactics that guarantee the presence of writing with a social function that makes sense for children and families. Tuning in with the children needs and interests, listeningand dialoguing with the families, continuous reflection among the literacy teachers were essential for the development of the work.

Keywords: family; literacy; literacy; remote teaching.

\section{Introdução}

Em maio 2020, no início da pandemia de Covid-19, um novo cenário se esboçava para todos. Diante dele, o CENPEC Educação e a Fundação Tide Setúbal se uniram para colaborar com um projeto de alfabetização para um grupo de alunos do primeiro ano do Ensino Fundamental da Escola Pedro Moreira, no Jardim La Penna, São Paulo.

Nessa demanda, reuniu-se um grupo de educadoras voluntárias que se dispuseram realizar o trabalho por vídeo-chamadas de celular, via WhatsApp. Dado a situação da pandemia, do fechamento da escola e da licença-maternidade da professora titular, o trabalho voluntário configurou-se como alternativa de acolhimento dessa população, a fim de permitir a vivência de experiências vinculadas às diferentes práticas de linguagem, particularmente de leitura e produção oral e escrita de gêneros discursivos. Dessa forma, encontros, por vide chamadas de WhatsApp, com duração de uma hora, duas vezes por semana, com vistas à reflexão sobre modos pelos quais as crianças puderam se apropriar de conhecimentos, colocando-se como sujeitos ativos da aprendizagem.

As instituições responsáveis estabeleceram comunicação entre as educadoras, escola e famílias. Assim surgiu o projeto Letra Móvel, do qual as autoras fazem parte.

No desenrolar dos atendimentos virtuais, a primeira percepção relevante foi a importância da parceria com a família: a presença do adulto ou membro da família disposto a colaborar com o educador do Letra Móvel. E foi em cima do tripé, educador, estudante e família que, ao longo dos meses, o trabalho evoluiu e se estruturou.

Com esse foco, pretendemos relatar alguns momentos preciosos de um dos elementos para o letramento, alfabetização e multiletramento dos encontros do projeto. Para inserir as crianças no mundo da escrita, a Base Nacional Comum Curricular (BNCC) chega para ajustar um importante foco, integrando duas tendências no ensino: aquela apoiada nas teorias de Letramento, que reconhece a centralidade do texto que tem como principal objetivo o trabalho com as práticas sociais de leitura e escrita, mas entende que a imersão no texto não é suficiente para a alfa- 
betização de todas as crianças, propondo então um trabalho sistemático para a aprendizagem do sistema de escrita alfabética. (SOARES, 2020)

Assim, trazemos cenários que evidenciam conflitos, diálogos, dificuldades, frustrações, interações e aprendizagens da tríade do Letra Móvel, a família

Estabelecer uma parceria com a família, através do vínculo afetivo e social para entender e, sobretudo respeitar, o espaço das aulas: sala, quarto, cozinha, um lugar de muitas funções, disputados e divididos com irmãos, avós, tios e às vezes até vizinhos. Nesse cenário, com cuidado e delicadeza, um espaço de aprender foi sendo estabelecido para descobrir interesses das crianças e seduzi-las para as atividades que propúnhamos - relacionadas à função social da escrita e muitas vezes diferentes de situações escolares, foi um desafio de persistência e paciência com o espaço do outro. Nesse novo cenário surgiram incômodos; Aula sem caderno? Sem cópia? Sem memorização? Com muita conversa? E isso lá era aula? Se a criança não sabe escrever, como pede para escrever? Aceita escritas tão erradas, e isso vai dar certo?

Novas habilidades tiveram que ser adquiridas na ótica das crianças - que tinham seis e sete anos de idade e ingressavam na primeira série do Ensino Fundamental. Tal como a concentração necessária por um tempo diverso da sala de aula, em casa, no papel de aluno, em ambiente de múltiplos estímulos, e acontecimentos. Numa alternância de papéis entre aluno e filho, ficavam em dúvida se nos atendiam e respondiam ao que perguntávamos na aula ou se aguardavam o consentimento da mãe, irmão. Para o equilíbrio dessa perspectiva instrumental tínhamos que ter um sensivel olhar pensante, ou seja, respeitar as condições concretas do espaço e dinâmica da família.

Alguns autores colaboraram para o entendimento dessa situação. Guizzo, Marcello e Muller (2020) afirmam que a quarentena da pandemia da Covid-19, deu origem a deslocamentos. Indicam que foi colocado em evidência o cotidiano inventado no tempo e no espaço, outrora centrado na escola. Ressaltam o novo cotidiano, de espaços reinventados na acepção de Certeau (1998). Essa situação aciona uma prática que coloca em cena a manutenção (de desigualdades, de hierarquias, de formas de controle), a criação de formas de existir e o fortalecimento (dessas mesmas desigualdades, hierarquias e formas de controle), bem como sua suspensão.

Concordamos que houve necessidade imposta pela situação de isolamento social de reorganização do espaço e do tempo. E pautados em Guizzo, Marcello e Muller (2020), salientamos que as práticas cotidianas, estão presentes por meio de ações que não são apenas reproduzidas, mas, sobretudo, criativamente inventadas (CERTEAU, 1998). Desta forma, nas práticas do Letra Móvel encontramos deslocamentos criativos de espaço e tempo para subsidiar nossas ações de ensino aprendizagem. Apresentaremos a seguir cenas que ilustram essas questões.

\section{Deslocamentos da escola para a casa}

A que trabalhava com $C$, se preparou com muita ansiedade para o encontro. Pediu até ajuda ao marido para adequar o espaço à aula. Pendurou o celular em um abajur para focalizar a mesa de trabalho, uma pilha de livros que seriam escolhidos para serem lidos, letras móveis, canetas, papéis, objetos necessários para um belo trabalho.

No horário combinado ligou para o celular da mãe inúmeras vezes, sem sucesso. Quando finalmente a mãe atendeu e disse: "ah! Estou no comércio, esqueci da aula". A ficou ao mesmo tempo decepcionada, frustrada nas suas expectativas, insegura em como encaminhar a situação, mas 
esperançosa de que isso se resolveria. No entanto, episódio semelhante ocorreu uma outra vez. A justificativa dada pela mãe do aluno nessa ocasião foi a de que estava no barbeiro levando $C$ para cortar o cabelo.

A tinha a expectativa de que o momento do encontro didático fosse importante para todos e pensou em qual caminho seguir para que os três estivessem sintonizados na mesma estação. Será que era descaso da mãe? C não estava se importando ou não desejava o trabalho?

Resolveu ter um diálogo com a mãe, e mostrou como preparava o espaço para o encontro, porque organizava os materiais e lembrou-se de um trecho do Pequeno Príncipe "muito antes de você chegar eu já estou te esperando".

Atualmente, a educadora chega pelo WhatsApp para o atendimento e C já está com a mesa arrumada, no início teve ajuda da mãe e com o tempo o próprio aluno assumiu a responsabilidade $e$ passou a organizar seu espaço com o mesmo capricho.

Esse relato demonstra como as expectativas do educador e da família eram diferentes. A educadora esperava que o espaço estivesse preparado para a aula, pois sua representação de espaço tinha sido construída profissionalmente. Por outro lado, a família de $\mathrm{C}$ não tinha a construção de estudo em casa, espaço do cotidiano familiar.

Entendemos que cada elemento desse trio - família, educador e criança - possuía alguma ideia do que seria esse momento de ensinar e aprender. Tinha a expectativa que fosse esperada pelo aluno e família com a mesma atenção que ela dedicava aos encontros, com espaço e tempo preparados para a aula. Por outro lado, para C e sua família a preparação de materiais e espaço ainda não estava entendida como determinação desse cenário educativo.

Diante da constatação da incompreensão dos deslocamentos existentes, da escola em casa, a educadora A toma a iniciativa e conta o que se passava com ela e de sua expectativa na situação de ensino aprendizagem. Constrói a chance de, através da linguagem, alterar o cenário, e possibilitar uma nova configuração espacial do ensino remoto e dual.

Para Vygotsky (1988), a linguagem é considerada uma atividade constitutiva do sujeito, do conhecimento e da própria linguagem. Através das mediações do outro e da linguagem, o sujeito organiza suas experiências, orienta sua ação e constitui seu pensamento. É importante considerar que tanto os objetos do mundo físico, quanto os papéis no diálogo e as próprias categorias linguísticas não devem ser tomados como existindo a priori. Neste caso, eles se instauraram e se construíram na interação da criança e seus interlocutores, sendo a dialogia estruturante do processo de construção linguística e comunicativa.

Esse processo de apropriação, segundo Rezende (1997) através do qual um processo interpessoal é transformado em um processo intrapessoal, desenvolve-se pela/na linguagem. Os signos que estão presentes no plano Inter psicológico são apropriados pelo indivíduo e se transformam em intrapsicológico. Por tanto, para que constituam a consciência, são necessários processos de mediação do outro, dos signos e dos objetos da cultura. Dessa forma, entendemos que estamos diante do conceito da lei de Dupla Formação citada por Vygotsky (1988, p. 64), segundo a qual "as funções do desenvolvimento da criança aparecem duas vezes: primeiro no nível social e, depois, no nível individual; primeiro entre pessoas (interpsicológica) e, depois no interior da criança (intrapsicológica)".

Concluímos a análise dessa cena, com um recorte significativo dos deslocamentos espaciais e temporais e da importância da comunicação através da linguagem oral, entre a 
escola e a casa, entre o educador e o educando e do papel da família como colaboradora do processo do Letra Móvel. Mudanças e desafios relevantes para a perspectiva de todos os atores envolvidos.

\section{Deslocamentos da casa para a escola}

$M$ relata que, quando deu início às aulas no ano passado, $Y$ tinha 6 anos. Assistia às aulas com sua irmã que estava prestes a completar 10 anos na ocasião. Vamos ao relato:

Ele é muito dependente da irmã, espera que ela faça tudo por ele. Adentramos na intimidade das casas, o que merece muito cuidado e respeito. As aulas eram realizadas no quarto, com as crianças sentadas na cama da mãe. Y vinha para a aula chupando chupeta e tinha pouco interesse nas atividades, mas gostava muito de ouvir histórias. Tinha uma escrita pré-silábica e a única palavra estável era SONIC, seu personagem preferido.

Aos poucos, fomos organizando o lugar, a mãe usava uma bandeja bem grande para funcionar como uma mesa, mas ficavam a maior parte do tempo sentados na cama. Y só tirava a chupeta para dar alguma resposta e se o dia estivesse muito frio, queria deitar-se, dificultando nossa interação. Fui introduzindo parlendas e atividades expressivas, mas o espaço era muito exíguo.

Certo dia, perguntei para a mãe se Y iria para a escola de chupeta, e ela disse que não. Então com delicadeza, mas firmeza, expliquei que nós estávamos em aula e que ele não deveria usar a chupeta em nossos encontros. Ele passou a vir sem ela, mas não prestava atenção, pois só queria que a aula acabasse para poder pegá-la. Algumas vezes em que precisei conversar com a mãe depois da aula, ele corria para pegar a chupeta.

O progresso era lento, mas o pai acabou proibindo a chupeta durante o dia e foi muito bom porque sua atenção começou a melhorar. Fomos aos poucos, trazendo-o para ao mundo da leitura e da escrita. Ele se apaixonou pela história dos Três Lobinhos e o Porco Mau. "Lia" a história incorporando as marcas do discurso escrito. Queria ler em toda aula e se eu tivesse outro planejamento, ele se dispersava. Sua atenção precisava ser trabalhada sempre.

No momento em que se mudaram para uma casa mais espaçosa pudemos fazer muitas atividades lúdicas com o grupo musical Palavra Cantada, e outros. Y foi se soltando cada vez mais, embora continuasse extremamente dependente da irmã e da mãe. Conseguimos fazer algumas atividades de pesquisa, de escrita espontânea e jogos diversos.

Na volta do recesso, tive a boa notícia de que ele havia deixado a chupeta... Sua autonomia vinha crescendo a cada encontro...

Nesta cena vemos com clareza como o hábito da chupeta, comumente usada em espaços íntimos, e o aglomerado de pessoas espontaneamente presentes na sala durante as aulas, foi sendo modificada, ou melhor, sendo deslocada para um espaço externo e social, promovida pelos conteúdos abordados e postura da educadora do Letra Móvel. Assim, o tempo de usar a chupeta foi suprimido e o espaço de aula foi delimitado.

Os atores, $\mathrm{Y}$, pais e $\mathrm{M}$ foram, através de ações criativas, cada um a seu tempo, construindo uma nova relação de aprendizagem, resinificando o espaço físico e as interações, discriminando comportamentos próprios de casa e da escola, por conseguinte com deslocamentos necessários para cada um deles. 
Neste cenário, Lonhares e Enumo (2020) refletem sobre o desenvolvimento infantil na pandemia da Covid-19, chamam a atenção de que eventos podem alterar o curso do desenvolvimento humano. Entendem que esse evento provoca contexto caótico e estressor, que se reflete no sistema familiar e no desenvolvimento das crianças.

Diante das cenas acima descritas e analisadas, notamos deslocamentos mediados pelas educadoras do Letra Móvel. Perante esses desafios, com o intuito de colher dados para nosso trabalho e aprimorar o processo de alfabetização e letramento, tentamos uma nova estratégia e propusemos encontros remotos com as famílias.

\section{Construímos com delicadeza ou aprendemos a delicadeza}

Em todos esses relatos percebemos que aos poucos as portas foram sendo abertas e os protocolos foram se estabelecendo. Os familiares puderam expressar suas desconfianças: "muita conversa, eles (crianças) estão te enrolando para não fazer tarefa?" E puderam entender que nossa metodologia de trabalho valorizava o desenvolvimento da oralidade e que dessa forma íamos nos aproximando das crianças e entendendo as familiais e seus interesses.

Um dia, quando a professora já estava com livros a tiracolo para ler, letras móveis para construir palavras e a música preferida da T, a irmã, a mãe atende ao telefone por vídeo e diz que não será possível ter aula naquele dia, pois ela havia conseguido um trabalho de embalar maquiagens em caixas que seriam enviadas pelo correio. A sala estava repleta de caixas vazias e produtos para serem embalados. Essa mãe estava diante de um dilema "Como equilibrar a sobrevivência com o lugar de mãe? A oportunidade de ler com textos em situações reais de uso foi oferecida para todos nós. Cabia à professora sugerir para mãe e filha uma atividade de leitura logográfica - reconhecimento global de palavras ligadas ao contexto gráfico, reconhecer os produtos: bases, cremes, batons, lápis etc. e ajudar a mãe nesse trabalho. Esse acontecimento inesperado possibilitou a todos um deslocamento de situações de ensino e aprendizagem já cristalizadas. A mãe que pode reconhecer um saber na filha que passou a colaborar com ela, a criança que se descobriu capaz de uma tarefa de tão grande importância, além de exercitar-se nessa estratégia de leitura. A professora que encontrou situações reais de uso da escrita.

Por vezes as famílias veem um abismo cultural entre a sua realidade social e a escola. Assim, submetem-se passivamente às solicitações desta instituição, exercendo sobre o filho uma enorme pressão em termos de exigências, por vezes desqualificando suas reais potencialidades para aprender (Pitombo,2009)

Alguns familiares demonstraram enorme paciência em explicar, compartilhar, reconhecer o valor das atividades, outros, deixavam clara a dificuldade de ver o filho não saber dar uma resposta. Nesse caso, se antecipavam e realizavam pelos filhos a atividade, com isso, tínhamos dificuldade em dar o tempo necessário para a dúvida, em colaborar com as crianças ajudando-as a pensar e não fazendo por elas.

Como deveríamos nos dirigir ao mesmo tempo para pais e filhos, incentivando uns, interrompendo outros? Nos demos conta que pais raramente vivem a experiência de testemunhar seus filhos durante o processo de aprendizado, com as frustrações e erros próprios da construção do saber: Um processo custoso, sofrido, repleto de insegurança e ansiedade. Alguns ficavam muito aflitos, talvez se lembrassem de suas experiências escolares? Queriam rapidamente responder pelos filhos. Nessa situação identificamos a transferência de desejo, conceito freudiano, discutido por Kupfer (1992) quando aborda as relações educacionais, A autora indica que "Transferir é então atribuir um sentido especial àquela figura determinada pelo desejo" (p. 91). Os pais ou 
familiares transferiam assim seu desejo de estudantes para as crianças ou, também seus desejos transferidos enquanto estudantes.

Nos encontros com as famílias, em 2020, obtivemos dados que serviram para análise, reflexão e aprimoramento do projeto Letra Móvel. Ressaltamos a seguir alguns pontos indicados pelos familiares nos encontros realizados, e a seguir uma análise e reflexão com o intuito de ampliar a leitura do cenário da atuação do Letra Móvel.

Dificuldade em acompanhar as tarefas escolares; estranham a linguagem. Nesse aspecto cabe indicar a disparidade na comunicação da linguagem entre escola e as famílias. Identificamos efeitos da história da escolaridade dos pais na vida da criança. Tinham vergonha de não saber; Irritação, impaciência. Fala pela criança. Segundo Batista, Silva (2012) indicam que os pais em geral, realizam acompanhamento escolar nos anos iniciais do ensino fundamental, nota-se, na população de território vulnerável, práticas de acompanhamento escolar, dado o domínio desses conhecimentos. Dificuldade de ver o filho não saber. "Ele é tudo que tenho e não gosto". O cenário da competividade do mercado se faz presente na idealização do filho. No entanto pode a criança sofrer pressão familiar para corresponder ao padrão. (Pitombo, 2009). Aprendizagem seguida de largo sorriso de orgulho e alegria. A alegria para Fernandez (2000) é critério de saúde no processo de aprendizagem.

Em outro encontro com famílias, via remota, em 2021, constatamos uma série de mudanças; reconhecimento das dificuldades iniciais em acompanhar as escritas das fases da alfabetização de maneira diferente da que aprenderam; novas aprendizagens, como, incentivo da autonomia das crianças para pensar a escrita; transformação das relações pessoais na família, como a colaboração entre pares para aula e leitura de livros. Relataram mudanças nas relações familiares em assuntos ligados ao ensino e a aprendizagem. A emoção de agradecimento de mútuos aprenderes encerrou nosso encontro, com a certeza de que muitas outras aprendizagens estão por vir.

\section{Referências}

FERNANDEZ, A. Psicopedagogia em psicodrama: hablando el jugar. Buenos Aires; Nueva Vision, 20000.

GUIZZO, B. S.; MARCELLO, F. A.; MULLER, F. A reinvenção do cotidiano em tempos de pandemia. Educ. Pesqui., São Paulo, v. 46, e238077, 2020. Available from <http://www. scielo.br/scielo.php?script=sci_arttext\&pid $=$ S1517-97022020000100402\&lng=en\&nr $\mathrm{m}=\mathrm{iso}>$. access on 20 May 2021. Epub Aug 10, 2020. https://doi.org/10.1590/s16784634202046238077.

KUPFER, M. C. - Freud e a Educação: o mestre do impossível São Paulo: Editora Scipione, 1992.

LINHARES, M B M E NUMO, S R F Reflexões baseadas na Psicologia sobre efeitos da pandemia COVID-19 no desenvolvimento infantil. Estudos de Psicologia (Campinas) [online]. 2020, v. 37 [Acessado 10 junho 2021], e200089. Disponível em: <https://doi.org/10.1590/19820275202037e200089>. Epub 05 Jun 2020. ISSN 1982-0275. https://doi.org/10.1590/1982$0275202037 \mathrm{e} 200089$.

PITOMBO, E. M. - Família, psicopedagogia e pós-modernidade. Cad. Psicopedag. São Paulo, v. 6, n. 11, 2007. Disponível em <http://p sic.bvsalud.org/scielo.php?script=sci_ arttext\&pid=S167610492007000100006\&lng=pt\&nrm=iso>. Acessos em 20 maio 2021. 
REZENDE. S. M. O processo reflexivo do professor sobre jogos interacionais em narrativas de histórias. FEUSP. AGOSTO/1997.

SOARES, M. - ALFALETRAR: Toda a criança pode aprender a ler e escrever. São Paulo: Contexto, 2020.

VYGOTSKY. L S. A Formação Social da Mente. São Paulo: Martins Fontes, 1998. 